\title{
The effects of tides on swash statistics on an intermediate beach
}

\author{
R. M. C. Guedes, ${ }^{1}$ K. R. Bryan, ${ }^{1}$ G. Coco, ${ }^{2}$ and R. A. Holman ${ }^{3}$ \\ Received 15 September 2010; revised 12 December 2010; accepted 14 January 2011; published 13 April 2011.
}

[1] Swash hydrodynamics were investigated on an intermediate beach using runup data obtained from video images. Under mild, near-constant, offshore wave conditions, the presence of a sandbar and the tidally controlled water depth over its crest determined whether most of the incoming waves broke before reaching the shoreline. This forced a change in the pattern of wave energy dissipation across the surf zone between low and high tide, which was reflected by changes to swash on time scales of a few hours.

Significant runup height $(R s$, defined as 4 times the standard deviation of the waterline time series), was found to vary by a factor of 2 between low tide, when most of the waves were breaking over the sandbar $\left(R s / H s \approx 1.5\right.$, where $H_{s}$ is the offshore significant wave height) and high tide, when the waves were barely breaking $(R s / H s \approx 2.7)$. The increase in wave energy dissipation during low tide was also associated with changes in swash maxima distribution, a decrease in mean swash period, and increasing energy at infragravity frequencies. Bispectral analysis suggested that this infragravity modulation might have been connected with the presence of secondary waves.

Citation: Guedes, R. M. C., K. R. Bryan, G. Coco, and R. A. Holman (2011), The effects of tides on swash statistics on an intermediate beach, J. Geophys. Res., 116, C04008, doi:10.1029/2010JC006660.

\section{Introduction}

[2] The swash zone is the interface between land and ocean where the waves intermittently cover the beach. The time-varying location of the shoreline water level within this region, usually termed runup [Guza and Thornton, 1982; Holman and Sallenger, 1985; Ruggiero et al., 2004] defines the cross-shore extent and the elevation that can be flooded for a specific tidal level. Runup is of great importance for coastal planners, who want to define appropriate and practicable shoreline setback criteria, for coastal engineers, who are interested in designing coastal structures, and for researchers studying the physical processes contributing to beach erosion/accretion [Butt and Russell, 2000; Elfrink and Baldock, 2002].

[3] Runup is commonly decomposed into a quasi-steady super elevation above the still water level (setup) and the fluctuations about such super elevation (swash) [Guza and Thornton, 1982; Holman and Sallenger, 1985; Stockdon et al., 2006]. The swash is composed of two distinct phases, an upslope, landward directed, flow (usually called uprush) and a downslope, seaward directed flow (normally known as backwash). Although there is a continuum of energy in swash spectra, they are commonly divided into incident $(0.33$ to $0.05 \mathrm{~Hz})$ and infragravity frequencies $(0.05$ to

\footnotetext{
${ }^{1}$ Department of Earth and Ocean Sciences, University of Waikato, Hamilton, New Zealand.

${ }^{2}$ National Institute of Water and Atmospheric Research, Hamilton, New Zealand.

${ }^{3}$ College of Oceanic and Atmospheric Sciences, Oregon State University, Corvallis, Oregon, USA.

Copyright 2011 by the American Geophysical Union. 0148-0227/11/2010JC006660
}

$0.003 \mathrm{~Hz}$ ). The incident band is normally more energetic in bore-dominated, steeper intermediate and reflective beaches [Holland and Holman, 1993; Raubenheimer and Guza, 1996], while low sloped dissipative beaches have been observed to have most of the swash variance within infragravity frequencies [Ruessink et al., 1998; Ruggiero et al., 2004].

[4] Swash characteristics depend on whether the incident waves reflect at the shoreline, or are dissipated offshore by breaking. Traditionally, infragravity waves are considered more likely to reflect [Miche, 1951] than waves whose spectra are dominated by the incident band. Nevertheless, recent measurements and modeling results have shown that the surf [Henderson and Bowen, 2002; Sheremet et al., 2002; Thomson et al., 2006; van Dongeren et al., 2007] and swash [Battjes et al., 2004] can be zones of infragravity dissipation. Miche [1951] hypothesized that under dissipative conditions runup will be saturated, and thus a maximum runup amplitude will be reached when the incident waves are just high enough to break. Further increase in offshore wave height increases the wave steepness and makes the waves break, dissipating their energy rather than reflecting it. Many field investigations on broadbanded swash have been interpreted based on Miche's saturation hypothesis. Huntley et al. [1977] calculated the spectra from vertical runup time series obtained in three different natural beaches and found the incident band to be saturated. This implies that the energy at the incident bands is proportional to $\beta^{4}$ and $f^{-4}$ (where $\beta$ is beach slope and $f$ is wave frequency) and independent of wave height. Some works [e.g., Mase, 1988; Ruggiero et al., 2004] have found a similar spectral shape for the saturated band of runup, whereas an $f^{-3}$ dependence has been observed by others [e.g., Guza and Thornton, 1982; Ruessink et al., 1998; Ciriano et al., 2005]. The implications 


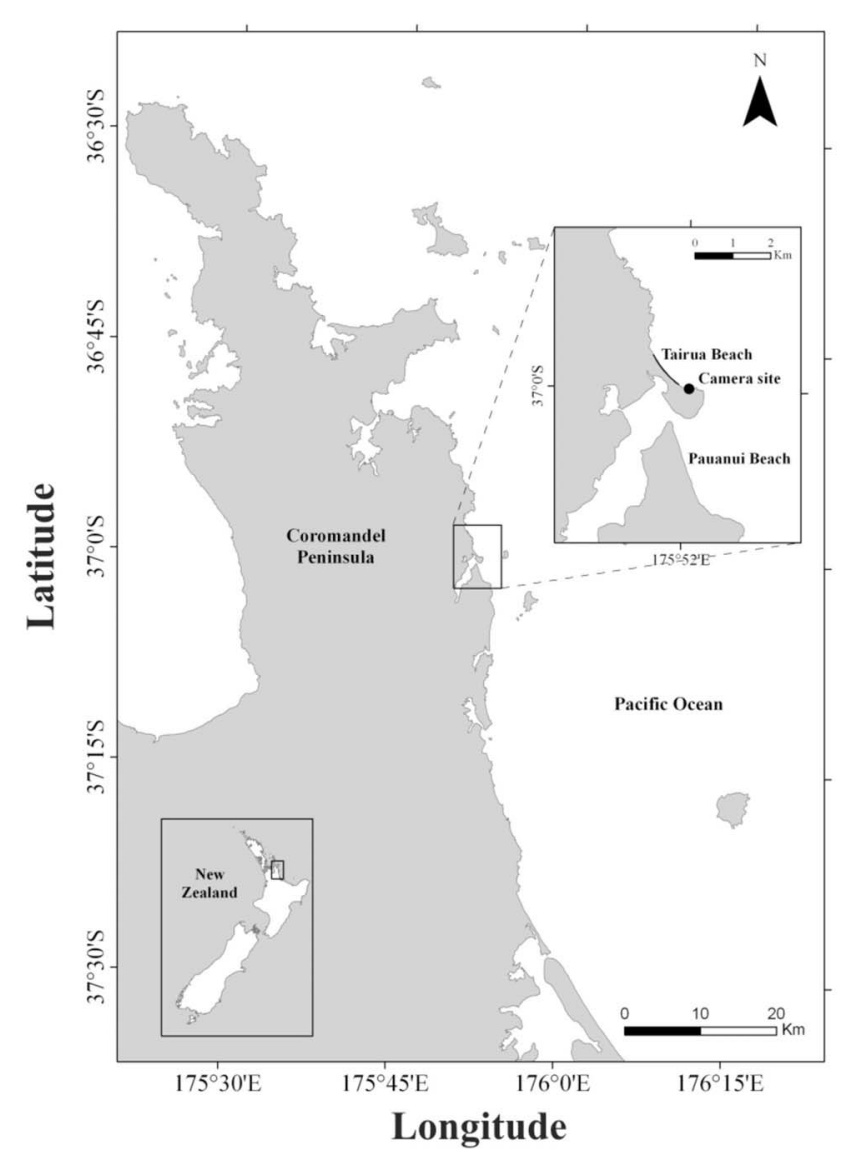

Figure 1. Field site location.

of different rates of incident energy decay are still not clear and it has been suggested that they might simply be related to different measurement methods [Raubenheimer and Guza, 1996]. Guza and Thornton [1982] measured swash oscillations on a mildly sloped beach and calculated the variance levels for incident and infragravity spectral ranges. Although incident swash energy was found to be independent of offshore wave height $H$ (i.e., the wavefield was saturated), positive linear correlation was observed between $H$ and low frequency energy at the shoreline, showing that the low-frequency component of the swash increases with increasing wave height in nonmonochromatic conditions, a behavior subsequently confirmed in other field studies [e.g., Holman and Sallenger, 1985; Raubenheimer and Guza, 1996; Ruessink et al., 1998; Ruggiero et al., 2004].

[5] The amplitude of incident swash oscillations has been shown to scale well with the nondimensional Iribarren number:

$$
\xi_{0}=\frac{\beta}{\left(H_{0} / L_{0}\right)^{1 / 2}}
$$

where $H_{0}$ and $L_{0}$ are deep water wave height and wavelength. Miche [1951] suggested that when $\xi_{0}$ is high, waves reflect at the shoreline and the swash has larger amplitudes, while for low $\xi_{0}$ the waves break and saturation conditions are expected. Field data have confirmed a linear relationship between the Iribarren number and incident runup height, especially for steeper intermediate and reflective beaches [e.g.,
Holman and Sallenger, 1985; Holman, 1986; Raubenheimer and Guza, 1996; Stockdon et al., 2006]. However, substantial variability is often observed around such relationship, possibly owing to other parameters affecting runup which are not accounted for by $\xi_{0}$ and also because the definition of a single value for beach slope might not be appropriate on some natural beach, where complex morphological features such as sandbars are often present [Holman and Sallenger, 1985].

[6] A potential source of variability in runup characteristics could be related to the presence of tides whose variations modulate a number of wave-related processes in the nearshore. For example, the breaking of waves inside the surf zone is a strong function of depth [Peregrine, 1983], and hence is likely to be modulated by the tide. Moreover, the presence of one or more sandbars in the surf zone will determine the characteristics of this breaking [e.g., Lippmann and Holman, 1989; van Enckevort and Ruessink, 2001; Aarninkhof et al., 2005; Haller and Catalán, 2009] and is therefore likely to affect swash hydrodynamics. However, the emphasis on offshore characteristics and beach slope introduced with Miche [1951] has meant the effects of sandbars in controlling the characteristics of runup have not been fully explored. The tidal influence in breaking will also control radiation stress gradients which are a function of the wave height gradients, and so long-shore current forcing will also be modulated at the tidal frequency inside the surf zone [Thornton and Kim, 1993]. Similarly, rip currents have been observed to be stronger at low tide [MacMahan et al., 2006]. Offshore of the breaking area, Okihiro and Guza [1995] observed infragravity energy within frequency bands of 0.01 and $0.04 \mathrm{~Hz}$ to decrease at low tide, which was hypothesized to be a result of changes in infragravity energy generation and propagation on the concave beaches onshore of the observations. In the surf zone, Thomson et al. [2006] observed similar modulations and attributed them to nonlinear energy transfers from low-frequency to higher-frequency motions, which were enhanced over the relatively flatter inner surf zone bottom profile at low tide.

[7] The aim of this work is to investigate the degree to which changes in swash hydrodynamics can also be related to tidal variations and the presence of a submerged sandbar on an intermediate beach. We use a data set of swash oscillations obtained on a natural beach during a period of mild nearly constant offshore wave conditions when the amount of wave breaking was clearly modulated by the tide and we show that some characteristics of swash such as amplitude, incident/infragravity variance levels and swash maxima distribution were also tidally modulated.

\section{Methods}

\subsection{Field Site}

[8] The field experiment was undertaken between 15 and 17 July 2008 at Tairua Beach, a $1.2 \mathrm{~km}$ long pocket beach located on the Pacific coast of New Zealand (Figure 1). This medium-coarse-grained beach has a fairly steep beach face slope of about 0.1 and is exposed to medium wave energy with average offshore significant wave height and mean spectral period of $0.9 \mathrm{~m}$ and $5.8 \mathrm{~s}$ [Gorman et al., 2003]. The tides are semidiurnal, with tidal ranges between 1.2 (neap) and $2 \mathrm{~m}$ (spring tides) and the system is normally 

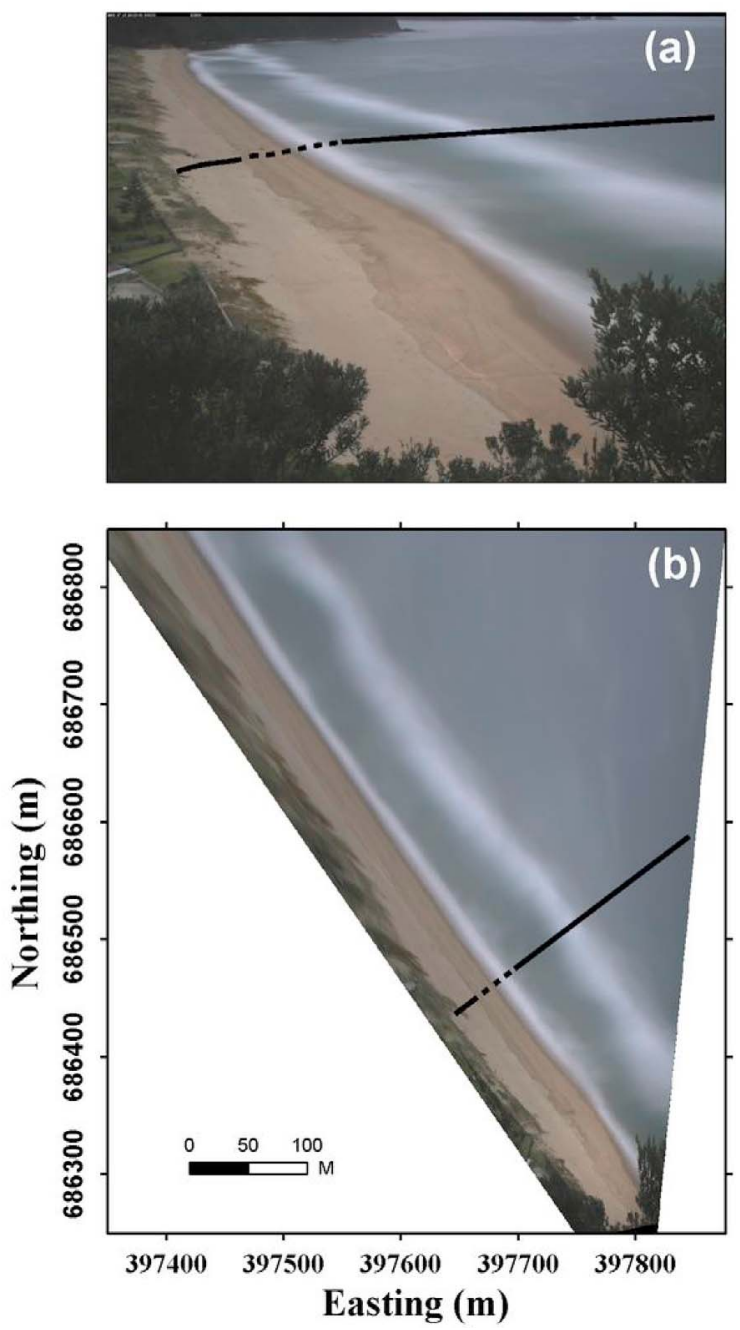

Figure 2. (a) Oblique image obtained at Tairua Beach on 16 July 2008 at 11.00 by averaging 600 individual frames recorded at $2 \mathrm{~Hz}$. (b) The same image rectified to a plan view using known geometric transformations. Black lines represent cross-shore transect where time stacks were created and location where the beach profile was surveyed (cross-shore range of the swash over the 3 days of field experiment is highlighted by the dashed lines).

classified as intermediate, with a rhythmic sandbar and strong rip currents often present [Bogle et al., 2000]. During the 3 day period of the experiment, the sandbar remained remarkably alongshore uniform, at a cross-shore distance of about $80 \mathrm{~m}$ from the shoreline (see the white alongshore bands in Figure 2 which are associated with the locations of preferred wave breaking over the sandbar and shoreline) and with water depths over the crest, estimated using the method developed by Plant et al. [2008], changing from about 1.1 to $2.2 \mathrm{~m}$ from low to high tide.

\subsection{Field Measurements}

[9] The data set presented here is composed of measurements of offshore hydrodynamic conditions, beach face topography and video images. The hydrodynamic variables were measured using an ADCP deployed at a water depth of about $12 \mathrm{~m}$. Time series of subsurface pressure were recorded every hour for $20 \mathrm{~min}$, at $2 \mathrm{~Hz}$ and converted to free surface elevation using linear theory. Offshore significant wave height $H s$ was calculated as $4 \sigma$, where $\sigma$ is the standard deviation of the free surface time series. Peak period $T p$ was determined as the inverse of the peak frequency from the spectrum. Hourly mean water level $\eta$ was calculated as the mean of each time series and adjusted to the local vertical datum. Peak direction was determined from the directional velocity spectrum obtained by the four independent acoustic sensors of the ADCP.

[10] A cross-shore beach profile was surveyed using a total station on $17 \mathrm{July,} \mathrm{covering} \mathrm{a} \mathrm{cross-shore} \mathrm{distance} \mathrm{of}$ $55 \mathrm{~m}$ between the backshore and the swash zone (Figure 3). The profile was extended offshore of the most seaward surveyed location by extending the linear fit through the lowermost measured points to create a profile that extended just beyond the likely lowermost location of low-tide swash elevation. The along-shore position of the profile is shown by the location of the black lines in Figure 2. Foreshore slope $\beta$ was calculated as the best linear fit of the measured profile between the locations of mean \pm 2 standard deviations of the shoreline positions for each data run $(95 \%$ of the data points assuming a Gaussian distribution).

[11] High-resolution images $(1528 \times 2016$ pixels $)$ were acquired continuously at $2 \mathrm{~Hz}$ during the daylight hours (e.g., Figure 2a), using a digital camera mounted at the southern end of the beach (Figure 1) at approximately $42 \mathrm{~m}$ above the sea level. Runup oscillations were extracted using a technique known as "time stack" [Aagaard and Holm, 1989], which consists of time series of pixel intensity, sampled along a cross-shore line defined on the images. The time stacks were created by determining the image coordinates of the measured cross-shore beach profile (e.g., Figure 2a) and collecting the values of light intensity at these coordinates into a row in the time stack matrices. Conversions between image coordinates and ground co-

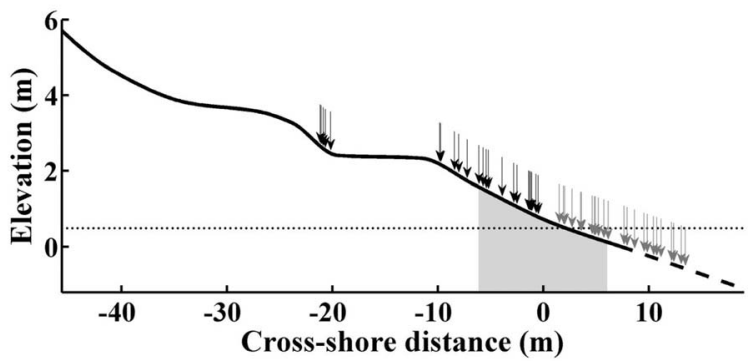

Figure 3. Beach profile surveyed at Tairua Beach on 17 July 2008 (solid line) with extension calculated as the line fit through the lowermost measured points (dashed line). Mean swash positions for the 25 data runs are delimited by the gray patch. Locations of mean $+(-) 2 \sigma$ of swash positions for the 25 data runs are highlighted by the black (gray) arrows. Dotted line at elevation of $0.5 \mathrm{~m}$ indicates still water level (i.e., setup not included) above which the "step" between cross-shore positions of -20 and $-10 \mathrm{~m}$ starts to become important for the swash (see text). Elevations are relative to New Zealand Geodesic Datum (NZGD). Cross-shore distances have origin at mean swash location for the 25 data runs and increase offshore. 

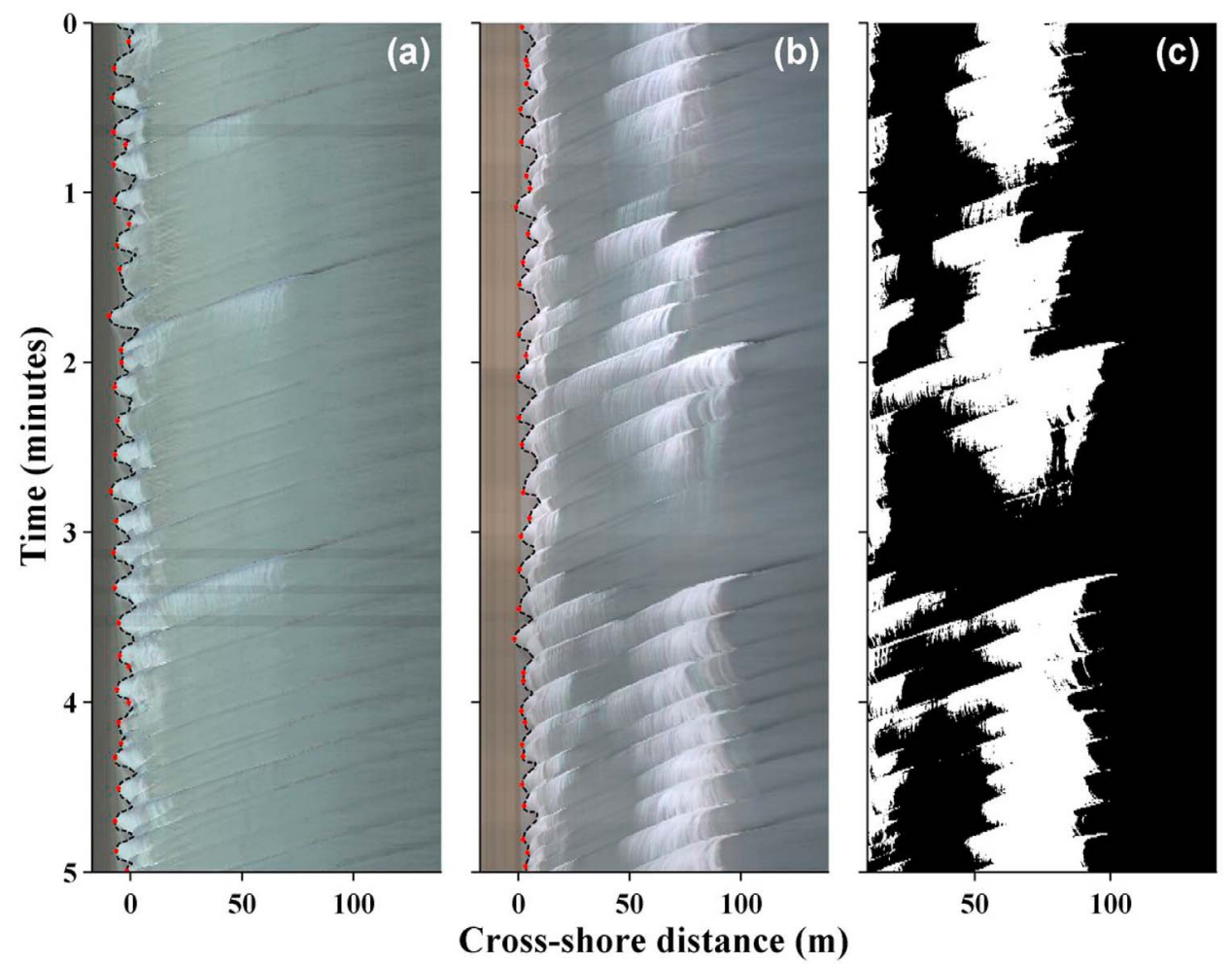

Figure 4. The 5 min fragments of the time stacks obtained at Tairua Beach (a) on 15 July 2008, at 15.30 near high tide and (b) on 16 July 2008, at 11.30 near low tide. (c) Binary time stack obtained from Figure 4b to quantify breaking using the method described in section 2 . Time increases from top to bottom of the images. Cross-shore distances have origin at mean swash location for the 25 data runs and increase offshore (see Figure 3). Dashed lines and red dots on Figures $4 \mathrm{a}$ and $4 \mathrm{~b}$ are digitized swash locations and located swash maxima, respectively. Sloping lines in the time stacks represent individual waves propagating toward the shoreline. Notice the stronger breaking (presence of white foam at cross-shore distances 50-100 m) for the time stack collected at low tide.

ordinates were made using the colinearity equations described by Holland et al. [1997] with corrections for lens distortions (e.g., Figure 2b). The vertical resolution of this technique, estimated by mapping the horizontal resolution to an elevation along the profile within the swash zone, varied mainly as a function of beach slope and was less than $3 \mathrm{~cm}$ (on average $1 \mathrm{~cm}$ ). The data set was broken into hour long time series, resulting in 25 time stacks created during the 3 days, with typically 7200 individual frames sampled in each.

\subsection{Data Analysis}

[12] The swash location was defined as the most shoreward edge of water identifiable on each line of the time stacks. It has been shown that this definition is consistent with swash measurements obtained using resistance wires deployed near bed [Holman and Guza, 1984; Holland et al., 1995]. The edge was detected using an image processing algorithm, developed to distinguish the sharp contrast observed between the swash front, typically characterized by the presence of white foam, and the darker sandy beach. Manual refinements were required in some images where the algorithm failed, which mostly happened due to poor contrasts arising from the absence of foam at the swash location, especially during the run-down phases of the swash cycles. Examples of digitized swash locations are shown in the time stacks obtained on 16 July 2008, at 1630 LT during high tide (Figure 4a) and at 1230 LT during low tide (Figure 4b). Time series of vertical runup elevation $R v$ were derived from the digitized swash locations since the cross-shore beach topography at the time stack location was accurately known from the surveyed profile.

[13] Swash statistics were calculated from the 25 hourly time series of runup elevation. Significant runup height $R s$ was estimated as $4 \sigma$ of the linearly detrended time series. Swash maxima $\zeta$ (e.g., Figure 4) were identified following Holland and Holman [1993] as the difference in elevation between any local crest and the setup level (mean level $\bar{z}$ of each time series). The local maxima were extracted using a modified version of the zero-crossing method. The time series showed clear evidence of patterns of smaller and larger waves, consistent with the broadband behavior that typically characterizes the swash, in which case standard zero-crossing analysis would not detect the smaller waves. We devised an objective method of detecting these smaller waves. The zero-crossing analysis was repeated 18 times, each time varying the zero level by $0.2 \sigma$ increments to a maximum/minimum of $\pm 1.8 \sigma$, each addition adding new waves to the result. The number of times the analysis was repeated was determined by the point at which changing 

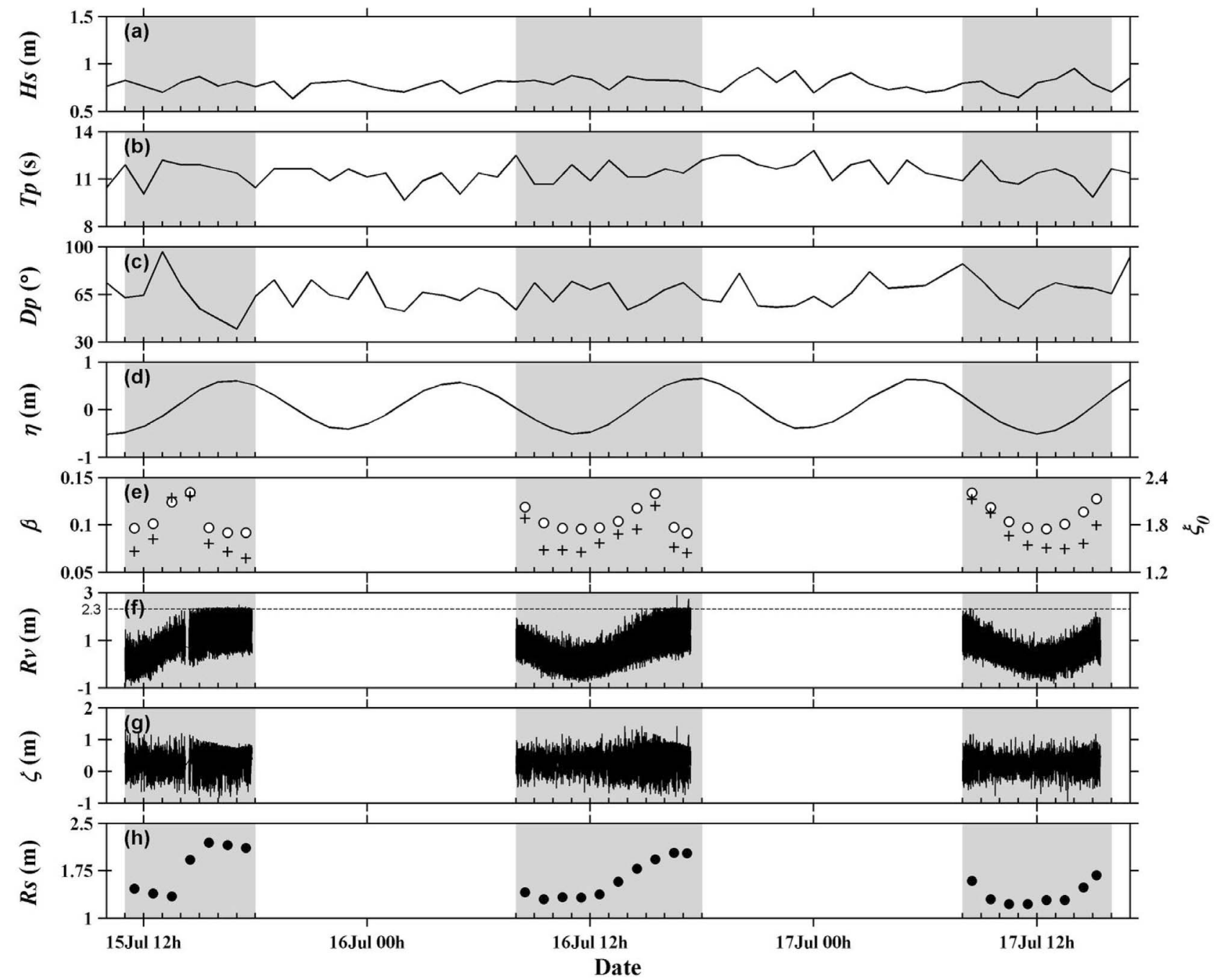

Figure 5. Time series of hydrodynamic and morphological parameters. Offshore characteristics (calculated hourly using the ADCP at $12 \mathrm{~m}$ depth): (a) significant wave height; (b) peak wave period; (c) peak wave direction; (d) mean sea level. (e) Beach slope calculated as the best linear fit of the measured profile between the locations of mean $\pm 2 \sigma$ of the shoreline positions for each data run (circles, left axis); Iribarren number calculated using equation (1) (pluses, right axis). (f) Time series of runup elevation relative to NZGD (solid line) with horizontal dashed line at $2.3 \mathrm{~m}$ highlighting elevation of beach step. (g) Time series of swash maximum relative to the mean (setup) level of each time series. (h) Significant runup height calculated hourly using the time series of runup elevation. Gray patches indicate daylight periods when the images were acquired.

the zero level no longer influenced the number of waves detected.

[14] Power spectra were calculated from each linearly detrended runup elevation time series, segmented into sections of $512 \mathrm{~s}$ (resulting in a bandwidth of $0.00195 \mathrm{~Hz}$ ) and tapered with a Hanning window (50\% overlap), giving typically 18 degrees of freedom. The energy density was partitioned into high $(f>0.05 \mathrm{~Hz})$ and low-frequency bands $(f \leq 0.05 \mathrm{~Hz})$ to account for the variance at incident and infragravity regions, respectively.

[15] The amount of breaking waves was estimated as the probability of breaking for each cross-shore location on the time stacks, based on the difference in pixel intensity between regions with (i.e., brighter pixels) and without the presence of foam (i.e., darker pixels). Thresholds were defined to separate breaking from nonbreaking pixels and create binary time stacks (e.g., Figure 4c), from which the probability of breaking of each cross-shore location was calculated. The thresholds were defined by randomly sampling pixel intensity values over regions visually identified as breaking and nonbreaking in each time stack, and calculating the average between the lowest "breaking" and the highest "nonbreaking" pixel intensities. This method does not distinguish the foam associated with the breaking wave roller from the residual foam left on the surface of the water after the waves break. However, the latter is also expected to be more frequent as wave breaking increases and this 

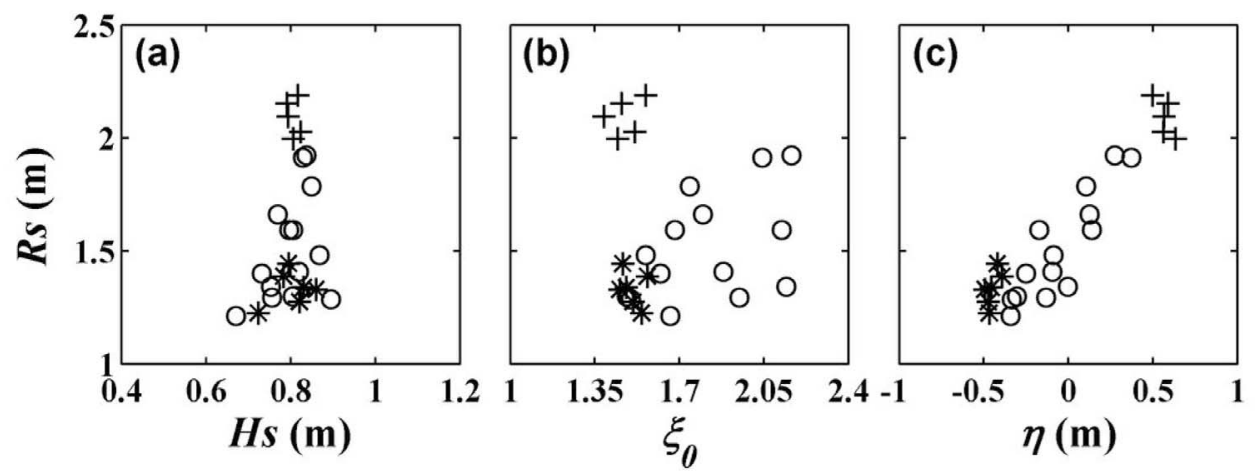

Figure 6. Regression plots of significant runup height $R s$ as a function of (a) offshore significant wave height, (b) Iribarren number, and (c) tidal level. Asterisks, circles, and crosses represent statistics from time series obtained during low tide (runs 1, 10-12, 21-22), midtide (runs 2-4, 8-9, 13-15, 18-20, 23-25), and high tide (runs 5-7, 16-17), respectively.

parameter is only used as a relative measure of breaking between high and low tide.

\section{Results}

\subsection{Hydrodynamic Conditions}

[16] An overview of the hydrodynamic conditions experienced during the field experiment is given in Figure 5. The offshore wave parameters barely changed, with gently sloping waves $\left(0.003<H_{0} / L_{0}<0.005\right)$ coming from east/ northeast with $H s<1 \mathrm{~m}$ and $T p$ between 10 and $12 \mathrm{~s}$ (Figures 5a-5c). The video recordings spanned three partial tidal cycles that ranged in elevation between -0.51 and $0.65 \mathrm{~m}$, with time stacks obtained over two high tides and three low tides (Figure 5d). Beach slope obtained from the profile shown in Figure 3 changed from 0.09 to 0.13 due to tidal-induced changes in water level moving the swash zone to different parts of the beach face (Figure 5e, circles). In general, beach slope follows the same trend as the tide for the time series in which $\eta<0.5 \mathrm{~m}$ (i.e., the swash zone was placed over the concave section of the profile, where crossshore position was greater than $-10 \mathrm{~m}$ in Figure 3 ). Higher tidal levels, however, resulted in the swash being located in the flat section of the profile (the step between cross-shore positions -20 and $-10 \mathrm{~m}$, where $\beta$ decreases). Iribarren number was mostly conditioned by changes in foreshore slope and ranged from 1.39 to 2.16 (Figure 5e, pluses), which characterizes reflective conditions and which is within the range of values reported by other authors [e.g., Raubenheimer and Guza, 1996]. Significant runup height changed by almost a factor of 2, from $1.2(1.5 \mathrm{Hs})$ to $2.2 \mathrm{~m}$ $(2.7 \mathrm{Hs})$ and displayed a consistent relationship with tidal levels (Figure 5h).

\subsection{Swash Statistics}

[17] The effects of environmental variables on swash oscillations were investigated by regressing $R s$ against $H s, \xi_{0}$ and $\eta$. Scatterplots of the regressions and correlation results are shown in Figure 6 and Table 1, respectively. No significant linear relation (at the 99\% confidence level) was observed between significant runup height and offshore significant wave height, which was expected given the small range of $H s$ during the experiment. This is also consistent with the results of Howd et al. [1991], who found the magnitude of the incident band measured in the trough to be a strong function of tide due to depth-dependent saturation over the crest. The lack of dependence of $R s$ on $\xi_{0}$, on the other hand, is somewhat surprising, considering the strong dependency of runup on both $\xi_{0}$ and $\beta$ reported in previous laboratory [Mase, 1988] and field studies [Holman and Sallenger, 1985; Ruggiero et al., 2004]. Nevertheless, there is a positive trend between runup and $\xi_{0}$ when the values obtained during high tide (runs 5-7, 16-17) are excluded from the analysis. Note that the beach slope drops considerably for these data runs while the runup height reaches the highest levels (Figure 5). This pattern is still more evident by regressing $R s$ against $\beta$ as the correlation coefficient $r^{2}$ jumps from $\sim 0$ to 0.52 when the high-tide runs are excluded from the analysis (not shown). The regression results emphasize that the main control on runup was the tide ( $r^{2}$ between $R s$ and $\eta$ amounted to 0.88 , significant at the $99 \%$ confidence level). It is difficult though to evaluate the contribution of the local slope to this relationship because the concave shape of the beach means that the influence of the slope would follow the same tidal trend below the beach step.

[18] In addition to the runup statistics, the swash maxima distribution $\mathrm{P}(\zeta)$, shown in Figure 7 was also found to change systematically over the different levels of tide. During low tide (e.g., time series 1,10 , and 22) $\mathrm{P}(\zeta)$ was slightly positively skewed (i.e., higher proportion of smaller waves). At the intermediate levels of tide (e.g., time series 2, 8,13 , and 19) $\mathrm{P}(\zeta)$ tended to assume a Gaussian distribution but became more and more negatively skewed as the tide increased. Finally, during high tide (time series 5-7, 16-17) the swash maxima distribution was consistently negatively skewed, with relatively few low waves compared to the

Table 1. Results of Regression Analysis ${ }^{\mathrm{a}}$

\begin{tabular}{lcrcr}
\hline$Y$ & $X$ & $m$ & $b$ & $r^{2}$ \\
\hline$R s$ & $H s$ & 1.59 & 0.32 & 0.06 \\
$R s$ & $\xi_{0}$ & -0.03 & 1.64 & 0 \\
$R s$ & $\eta$ & 0.8 & 1.61 & $\mathbf{0 . 8 8}$ \\
\hline
\end{tabular}

${ }^{\mathrm{a}} Y=m X+b$. Correlation coefficient squared $r^{2}$ significant at the $99 \%$ confidence level showed in bold. 


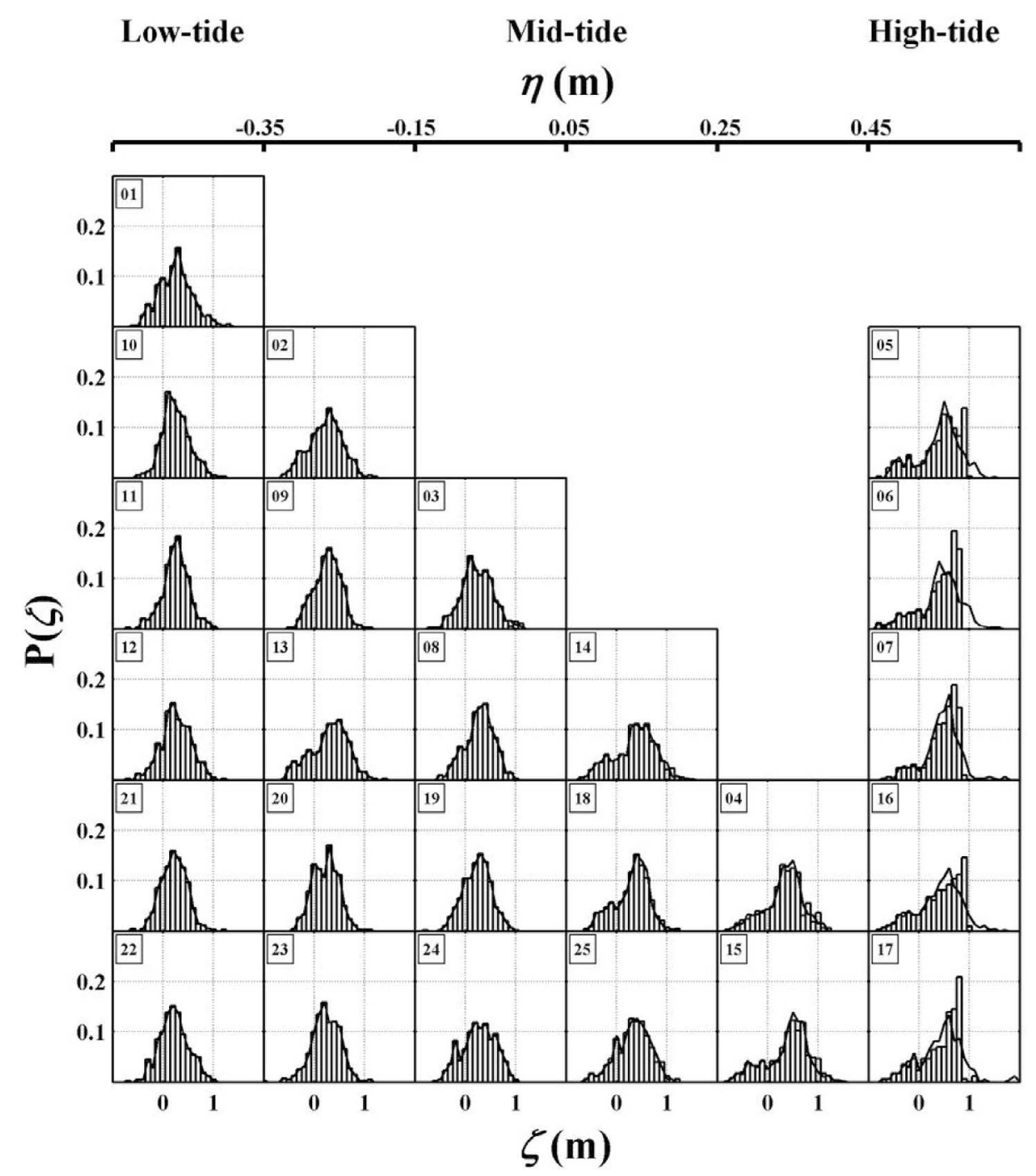

Figure 7. Swash maxima distribution $\mathrm{P}(\zeta)$, calculated for the 25 runup time series. The bars represent the distributions associated with the real time series, and the solid lines represent those obtained from time series derived by using a synthetic profile, where a linear fit of the lower beach face was extended shoreward to replace the beach step between cross-shore positions of -20 and $-10 \mathrm{~m}$. Each individual panel has been sorted according to the tidal level $\eta$ (top axis) associated with the respective run, which is indicated by the numbers in the top left corners.

other stages of tide. The dependence of skewness of swash maxima on tide is highlighted in Figure 8. The highly skewed distributions observed at high tide resemble cut off Gaussians at elevations correspondent to the flat part of the beach profile (step) between cross-shore positions of -20 and $-10 \mathrm{~m}$ (Figure 3 ; see also Figures $5 \mathrm{f}$ and $5 \mathrm{~g}$ ). The effect of the step on the swash distribution was assessed by deriving runup elevation time series with a synthetic profile, where a linear fit of the lower beach face was extended shoreward over the beach step. The flat-beach-corrected distributions, shown by the solid lines in Figure 7, are significantly different than the uncorrected statistics for the rightmost, high-tide panels, although they do not differ significantly over the other stages of tide.

[19] Time series of offshore and shoreline power spectra are shown in Figures 9a and 9b. Although both time series show little energy at the unsaturated infragravity frequencies, the swash spectra has a tidally modulated peak at incident frequencies (between 0.07 and $0.09 \mathrm{~Hz}$ ) that increases in energy with the tide, with the power ranging by an order of magnitude between high and low tide. This modulation does not happen offshore, where the spectral peak is centered at virtually the same frequencies as the runup spectra but the energy levels barely change with the tide. Conversely, the energy in the swash spectra at infragravity frequencies tends to increase from high to low tide, although virtually no energy at infragravity frequencies can be observed in $12 \mathrm{~m}$ depth. Whereas no tidal modulation in the offshore spectrum can be observed, the wave energy within the surf zone is obviously controlled by wave breaking according to the level of tide (Figure 9c). As the tide goes down, the waves start to break farther from the shoreline and 


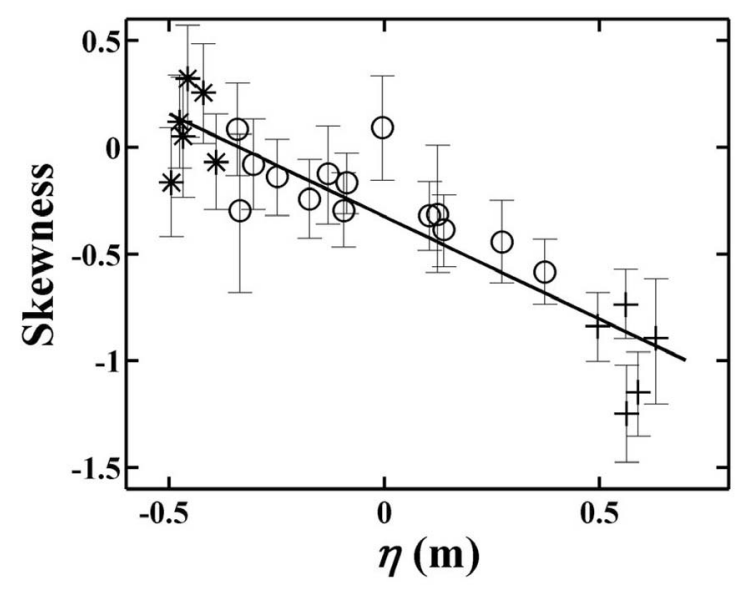

Figure 8. Skewness of swash maxima $(\gamma)$ as a function of tidal level. Solid line represents the best linear fit given by the equation $\gamma=-0.96 \eta-0.32\left(r^{2}=0.81\right.$, significant at the $99 \%$ confidence level). Asterisks, circles, and crosses represent statistics from time series obtained during low tide (runs 1, 10-12, 21-22), midtide (runs 2-4, 8-9, 13-15, 18$20,23-25$ ), and high tide (runs 5-7, 16-17), respectively. The $95 \%$ confidence bars were defined for each skewness estimate using a bootstrap technique in which 3000 new samples, drawn with replacement from the actual sample, were computed using a Monte Carlo algorithm. The confidence limits were estimated from the distribution of the skewness associated with these bootstrap samples for each of the 25 sets of swash maxima. the probability of breaking around the location of the sandbar increases. The majority of the waves were breaking during the lowest water levels which implied higher dissipation of the incident wave energy (consistent with observations of the swash spectra).

\section{Discussion}

\subsection{Spectral Analysis}

[20] We observed tidally modulated changes in the degree of wave breaking over the sandbar to have major implications to the properties of the swash spectrum. Figure 10 shows the swash and offshore variances partitioned into incident and infragravity frequencies and also the swash and offshore spectra averaged over low and high tide. At the incident band, not only was the magnitude of the peak affected by changes in wave breaking (Figures 9b, 10b, and $10 \mathrm{~d})$, but also the rate of energy decay. The slope of the saturated region of the spectrum, estimated by the best linear fit of the energy density between the peak frequency and $0.3 \mathrm{~Hz}$ (on a log-log scale) decayed at rates that varied between $f^{-4}$ and $f^{-3}$, with the steeper roll-offs normally associated with the mid-high tide, peaked spectra (Figure 11). Although in previous studies the differences in energy decay rate with increasing frequency have been attributed to different methods of runup detection [Guza and Thornton, 1982; Raubenheimer and Guza, 1996], it is possible that, for the present data set, the dominant effect is modulation of the degree of incident energy dissipation over the bar and the lowering of the incident spectral peak at low tide.

[21] In contrast to the energy at the incident band, the energy at infragravity band of the swash spectrum was enhanced at the lower stages of tide, even though offshore

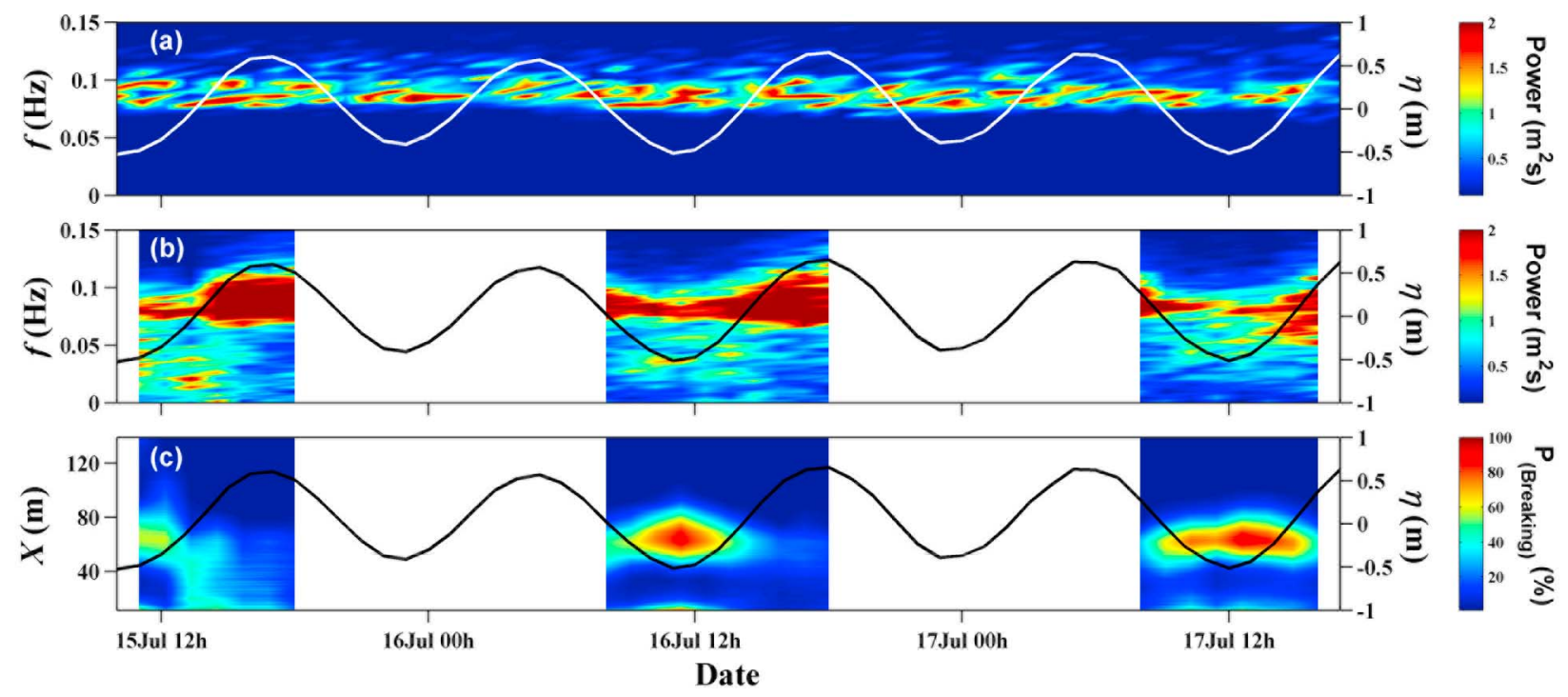

Figure 9. Time series of hydrodynamic properties with solid line (right axis) representing tide level. (a) Offshore wave spectrum time series calculated from the pressure time series recorded by the ADCP at $12 \mathrm{~m}$ depth. (b) Runup spectrum time series calculated from the runup time series. (c) Probability of breaking time series calculated as the probability of exceedance of a pixel intensity threshold that characterized the presence of foam on the time stacks for each cross-shore pixel location. Cross-shore distances have origin at mean swash location for the 25 data runs. 

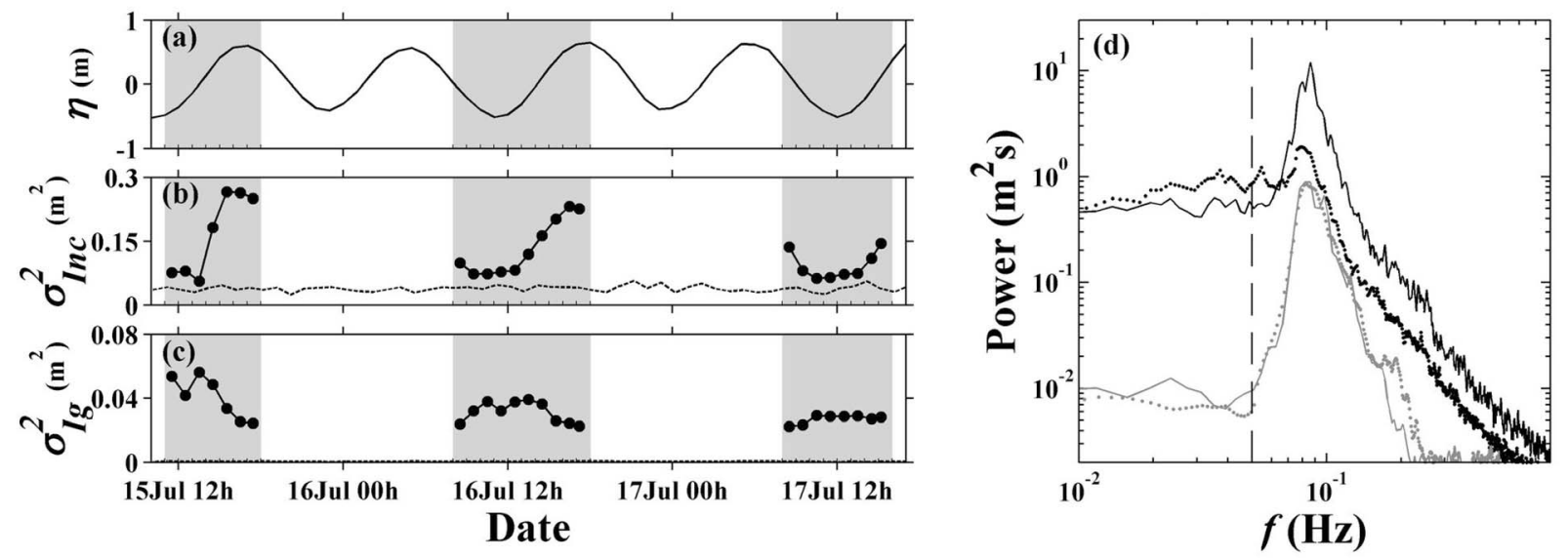

Figure 10. (a) Tide levels. (b) Runup (solid line with circles) and offshore (dotted line) variance $\sigma^{2}$ at the high-frequency $(>0.05 \mathrm{~Hz})$ region. (c) Runup (solid line with circles) and offshore (dotted line) variance at the low-frequency $(\leq 0.05 \mathrm{~Hz})$ region (offshore variance at the low region is hardly seen due to low values). Gray patches indicate daylight periods when the images were acquired. Note the different scales for $\sigma^{2}$ at high and low frequencies. (d) Average of spectra obtained during low tide (runs 1 , 10-12, 21-22, dotted line) and high tide (runs 5-7, 16-17, solid line), plotted on a log-log scale (runup spectra are shown in black, and offshore spectra are shown in gray). Vertical dashed line highlights frequency used to separate incident and infragravity variances.

energy at infragravity frequencies was very low and not observed to be tidally modulated as in other data sets [e.g., Okihiro and Guza, 1995; Thomson et al., 2006]. It is apparent in Figures 9 and 10 that the overall energy in the swash is being predominantly controlled by dissipation at incident frequencies, which have variance levels of about an order of magnitude higher than infragravity levels at high tide. However, infragravity variance tends to increase as the tide decreases and eventually energy levels at these two regions of the spectrum become of the same order of magnitude at low tide, suggesting that part of the energy lost from the incident band is not being dissipated but transferred to infragravity frequencies.

[22] Our observations are consistent with many other studies [e.g., Masselink, 1995; Ruessink, 1998a, 1998b; Baldock and Huntley, 2002; Janssen et al., 2003; Baldock, 2006] showing that wave breaking, in our case modulated by tides, is key to the increase of infragravity energy in the surf zone (and therefore swash). This is also consistent with the two most widely accepted mechanisms for infragravity generation as they both rely on wave breaking, either as a release of the onshore propagating bound wave, originated from gradients in radiation stress within wave groups [Longuet-Higgins and Stewart, 1964] or through the modulation in the breakpoint position [Symonds et al., 1982; Lippmann et al., 1997].

[23] Although the mechanisms mentioned above might have been associated with infragravity forcing in the surf zone at low tide, we observed in our data that secondary waves (with higher frequencies than incident) occurred at low tide when the infragravity energy increased (Figure 12a). The incident and secondary waves appear to combine at the beach face to modulate low-frequency oscillations. As can be seen in Figure 12a, there is an increasing number of wave crests shoreward of the sandbar location $(\sim 80 \mathrm{~m})$ at low tide.
These waves can be followed propagating toward the shoreline, where eventually they start climbing on the beach face before the backwash of the previous waves starts to take place. Although it is difficult to establish whether bore-bore interactions between these individual waves combine to result in runup time series characterized by higher energy at infragravity frequency, we notice that at high tide, where the

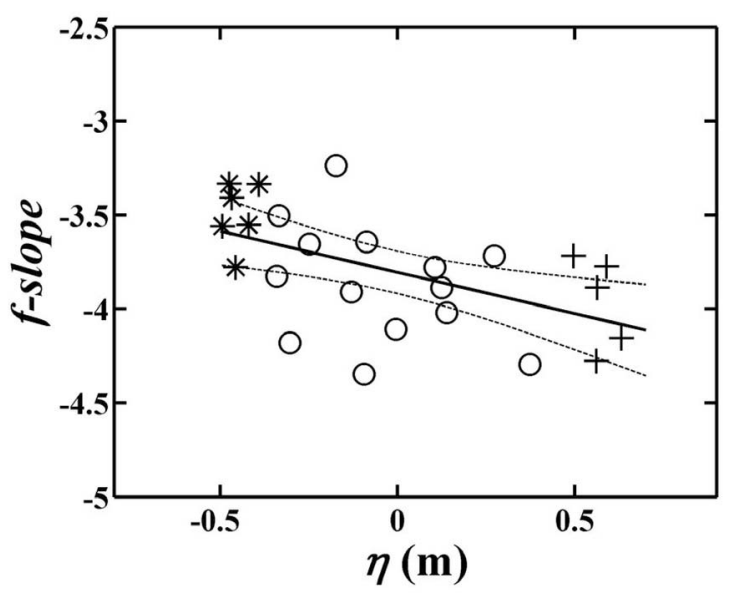

Figure 11. Regression plot of the slope of the saturated band of the runup spectra on a log-log scale $f$-slope as a function of tidal level, with the solid line representing the best linear fit given by the equation $f$-slope $=-0.44 \eta-$ $3.8\left(r^{2}=0.29\right.$, significant at the $99 \%$ confidence level $)$. Asterisks, circles, and crosses represent statistics from time series obtained during low tide (runs 1, 10-12, 21-22), midtide (runs 2-4, 8-9, 13-15, 18-20, 23-25), and high tide (runs 5-7, 16-17), respectively. The 95\% confidence interval for the regression analysis is shown by the dashed lines. 

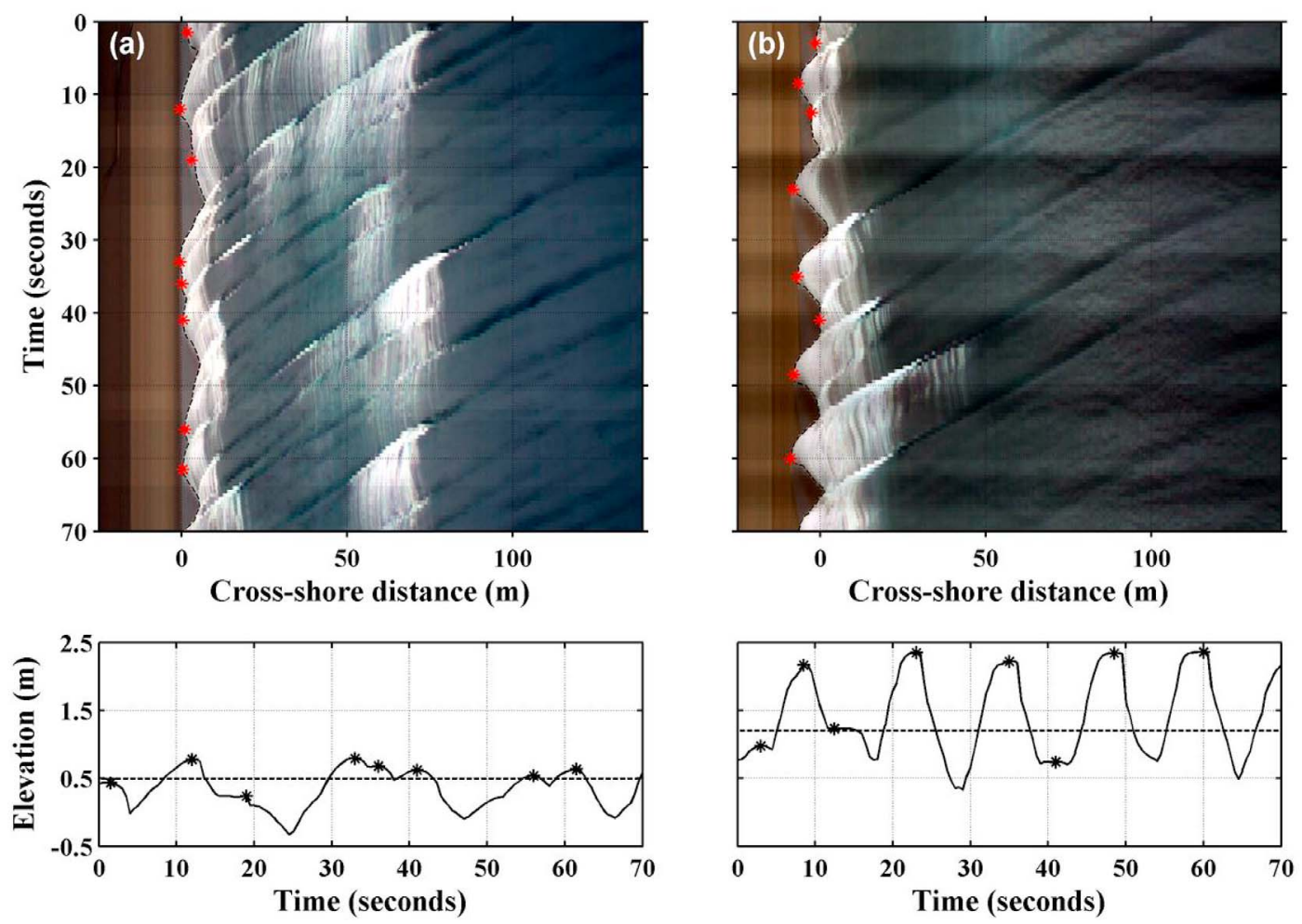

Figure 12. The $70 \mathrm{~s}$ fragments of time stacks obtained at Tairua Beach (a) on 17 July 2008, at 10.30 during mid-low tide and (b) on 16 July 2008, at 15.30 (top) during mid-high tide with (bottom) the respective time series of vertical runup elevation. Asterisks highlight the detected swash maxima. Dashed lines on Figures $12 \mathrm{a}$ (top) and $12 \mathrm{~b}$ (top) are digitized swash positions. Horizontal dashed lines on Figures 12a (bottom) and 12b (bottom) are mean runup elevation (setup level) for each hour long time series. Elevations are relative to NZGD. Cross-shore distances have origin at mean swash location for the 25 data runs and increase offshore.

increasing number of wave crests is not evident (Figure 12b), the infragravity signal disappears, and the oscillations at the shoreline are dominated by the incident peak (T $12 \mathrm{~s})$.

[24] The increase in the number of wave crests shoreward of the sandbar at the lower stages of tides could be a result of the decomposition of the primary wave motion into higher-frequency secondary waves over the bar. The generation of these secondary waves, as the primary motions propagate over the sandbar, has been previously reported in both laboratory [Beji and Battjes, 1993] and field experiments [Elgar et al., 1997; Masselink, 1998; Sénéchal et al., 2002], and according to Masselink [1998], might be a common process on barred beaches. Beji and Battjes [1993] showed that an increasing nonlinear transfer of energy between the primary and phase-locked, harmonic frequencies occurs as the waves propagate over the seaward, sloping face of the sandbar, becoming even stronger as they cross the flat section of it due to triple resonant interactions, and that these harmonics might be eventually released along the deepening shoreward section of the bar due to amplitude dispersion. It appears that these secondary waves might be important in controlling swash hydrodynamics, especially during low tide when the incident peak is increasingly dissipated by breaking.

[25] We investigated the low-tide increase in infragravity energy using higher-order spectral (bispectral) analysis.
Bispectral analysis has been successfully employed to study nonlinear transfer of energy between frequencies in both the surf [Elgar and Guza, 1985; Sénéchal et al., 2002] and the swash zone [Bryan and Coco, 2010]. The technique examines the phase locking between the oscillations at triplets $\left(f_{1}, f_{2}, f_{3}\right)$, where $f_{1}$ and $f_{2}$ are two basic frequencies and $f_{3}=$ $f_{1}+f_{2}$. If the modes are independent of each other, as is the case of a field of waves with random phases, no significant bicoherence between them is expected to be observed in the bispectrum. However, considering that swash cycles are somewhat parabolic, and the parabolic shape is composed of the sum of phase-coupled harmonics with frequencies $f, 2 f$, $3 f$ and so on, and zero phase, the bispectral signature of the swash might be expected to show significant bicoherence at $(f, f),(f, 2 f),(2 f, f)$ and so forth [e.g., Bryan and Coco, 2010, Figure 2].

[26] Figure 13 summarizes the bispectral results, averaged for time series obtained at low, mid and high tide. The peaks between the incident frequency (around $0.08 \mathrm{~Hz}$ ) and the harmonics can be observed as expected, although they are not strong and look smeared into a line. This is consistent with the results of Sénéchal et al. [2002], who found wave breaking to weaken the strength of the nonlinear couplings. There are also significant peaks in the bicoherence located at frequencies higher and lower than the incident peak. The higher peak was close to $(0.12,0.12 \mathrm{~Hz})$, which roughly 

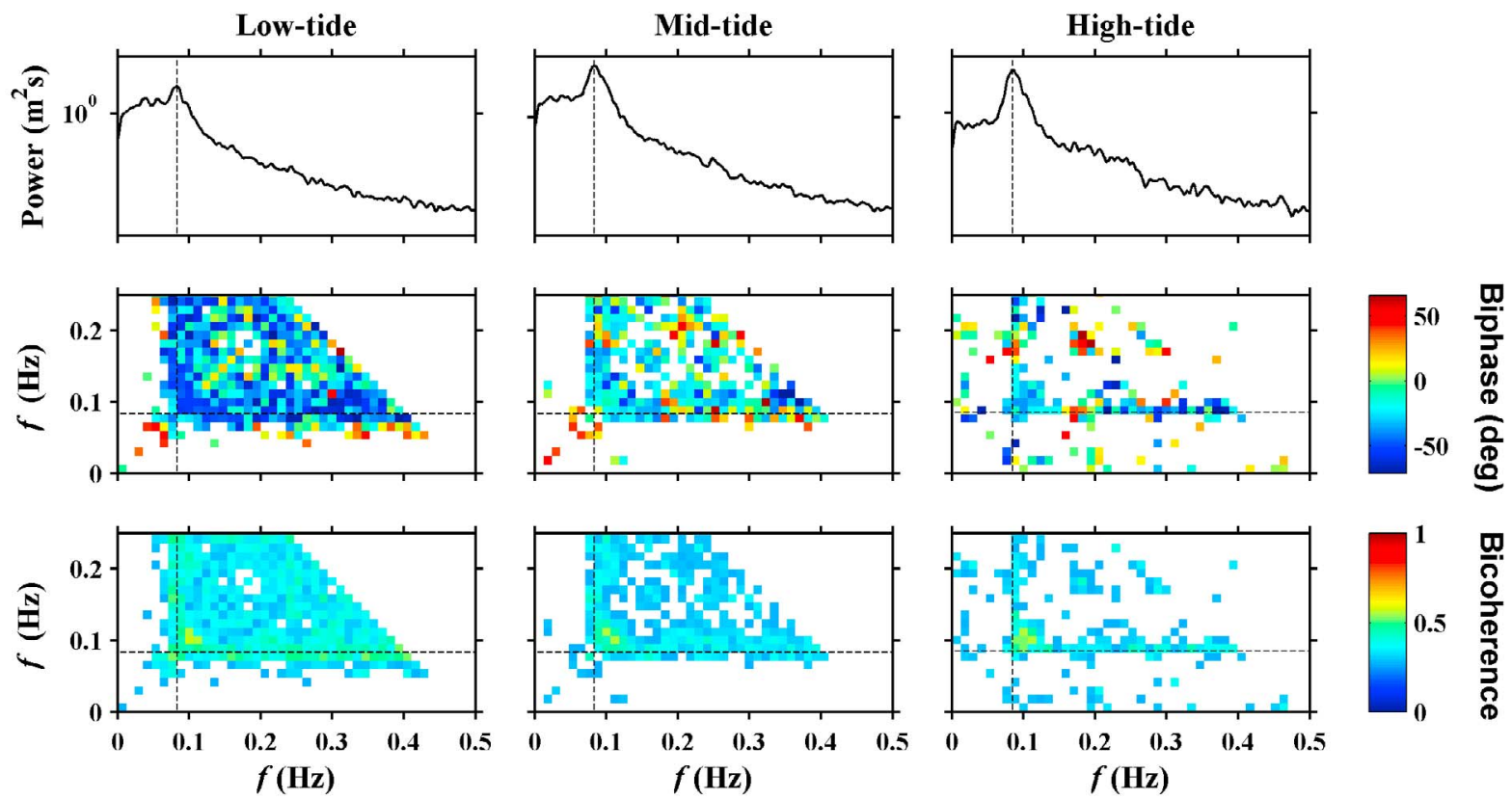

Figure 13. Runup spectra (top), biphases (mid) and bicoherences (bottom panels) averaged for time series obtained over (left) low-tide (runs 1, 10-12, 21-22), (middle) midtide (runs 2-4, 8-9, 13-15, 18-20, 23-25), and (right) high-tide (runs 5-7, 16-17). Black dashed lines highlight the peak frequency of the runup spectra shown on the top. Bispectra were calculated from each runup elevation time series after quadratic detrending, segmenting into sections of $512 \mathrm{~s}$ (1024 data points) and Fourier transforming, and the results were merged over 12 frequency bins, giving 84 degrees of freedom. Biphase and bicoherence signals below the $95 \%$ significance level have been blanked.

corresponds to the mean swash period (calculated in the time domain as the duration of the time series divided by the number of local maxima and found to vary from 8.5 and $9.5 \mathrm{~s}$ ). It is possible that these peaks are associated with swash interactions. Bryan and Coco [2010] showed bispectra generated from synthetic swash series in which each swash cycle was made dependant on the previous one. This interaction created an infragravity pattern in the time series caused by sequences of swash cycles (e.g., high-low-highlow crests). Because the incident wave ordering pattern was associated with the infragravity pattern, they were phase locked. Since the infragravity pattern was not symmetric (the higher incident waves occurred either at the end or beginning of a sequence), the infragravity signal had evidence of harmonics in the bispectrum corresponding to a sawtooth shape. In our case, the infragravity signal would appear to be at $0.06 \mathrm{~Hz}$ (with biphases between $-30^{\circ}$ and $-50^{\circ}$, indicating an asymmetric shape), and the harmonic at $0.12 \mathrm{~Hz}$ (with biphase shifting from $-30^{\circ}$ to $-60^{\circ}$ as the tide decreases). Note that there is a coherent low-tide signature in the bispectra at $f 1=0.06 \mathrm{~Hz}, f 2=0.08 \mathrm{~Hz}$. The $0.12 \mathrm{~Hz}$ coherence peaks also seem to be associated with the presence of the secondary waves at the shoreline, so it is possible that the coupling process transfers energy to a "real" wave. Alternatively the secondary waves might be related to shoaling and breaking processes in the surf zone. Observations of current and pressure just seaward of the swash would allow the swash interaction hypothesis to be tested more thoroughly.

\subsection{Swash Elevation}

[27] The absence of significant changes in offshore wave conditions during the field experiment (Figures 5a-5c, 9a, and 10) allowed us to control for effects of offshore wave height on runup and closely investigate the effects of other variables, such as beach slope and tide. Significant runup height $R s$ was found to be as high as $2.7 \mathrm{Hs}$ under nonbreaking conditions, with the ratio $R s / H s$ linearly decreasing to 1.5 at low tide when wave breaking was maximum. The incident band of the swash $R s_{\text {Inc }}$, which accounted for most of the swash amplitude, ranged from $\sim 1.2$ to $2.6 \mathrm{Hs}$ between low and high tide (Figure 14a). Although $R s_{\text {Ind }} / H s$ was not observed to scale with Iribarren number $\xi_{0}$ (Figure 14b), in disagreement with other observations [Holman and Sallenger, 1985; Raubenheimer and Guza, 1996], our results are consistent with the relationships obtained in these studies when breaking conditions were predominant. We found $\xi_{0}$ to range from 1.45 at low tide $\left(R s_{\text {Inc }} / H s \sim 1.2\right)$ to 2.16 at midtide $\left(R s_{\text {Ind }} / H s \sim 2.0\right)$, when the swash was oscillating along the steepest section of the profile just under the step (see Figure 5e), which is within the range observed by these authors for equivalent Iribarren numbers [see Holman and Sallenger, 1985, Figures 7 and 10; Raubenheimer and Guza, 1996, Figure 5]. Nonbreaking conditions, on the other hand, resulted in the magnitude of normalized incident (and total) significant runup height to be consistently higher compared to these predictions (Figures $6 \mathrm{~b}$ and $14 \mathrm{~b}$ ), suggesting that under mild offshore wave conditions the presence of a sandbar affects the magnitude of the swash. Our 

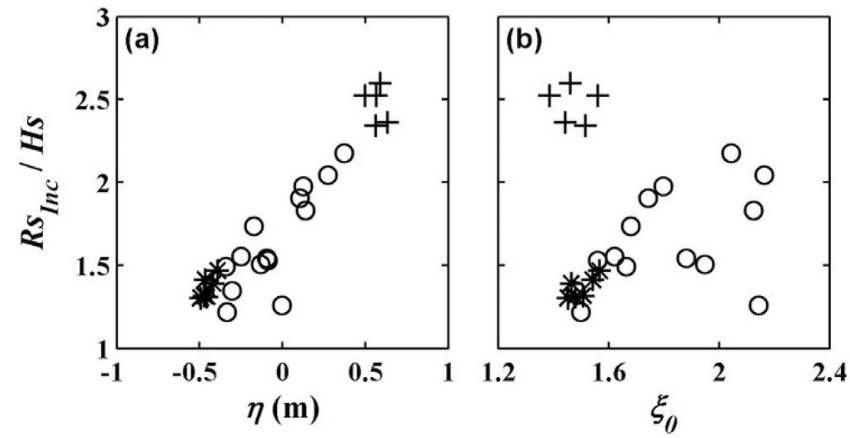

Figure 14. Regression plots of significant runup height for the incident frequency band $(>0.05 \mathrm{~Hz})$ normalized by offshore significant wave height, as a function of (a) tidal level and (b) Iribarren number. Asterisks, circles, and crosses represent statistics from time series obtained during low tide (runs 1, 10-12, 21-22), midtide (runs 2-4, 8-9, 13-15, $18-20,23-25$ ), and high tide (runs 5-7, 16-17), respectively.

results differ substantially from observations under more dissipative conditions, where the incident band is saturated and most of the swash energy is at infragravity frequencies (e.g., $R s / H s \sim 0.7$ [Guza and Thornton, 1982], Rs/Hs $\sim 0.18$ [Ruessink et al., 1998], and Rs/Hs 0.26 to 0.61 [Ruggiero et al. [2004]).

[28] The tidal modulations have been observed to be manifested not only in the amplitude of swash oscillations, but also in the skewness of swash maxima distribution. The strong negative skewness, characteristic of high-tide time series (Figures 7 and 8) was shown to be related to the presence of the beach step at the elevation of about $2.3 \mathrm{~m}$ (Figures 3, 5f, and 7). At high tide, this abrupt decrease in beach slope seems to limit vertical swash excursions farther above that height by both increasing bottom friction (the swash runs over a longer distance to reach a given elevation) and water percolation (the sand is likely to be unsaturated at this location). Without the beach step, one would have expected that even higher variance levels could have been observed at high tide, when most waves were not breaking over the sandbar. The slightly positive skewness in the swash maxima distribution at low tide, on the other hand, suggests a higher proportion of small negative maxima (smaller than the setup level). Indeed, Holland and Holman [1993] observed an increase in the proportion of negative $\zeta$ as the spectral width of the time series increased, which agrees with the noticeable spectral broadening observed during low tide in this data set (see Figure 9b). The enhanced number of small swash maxima during low tide is also consistent with the observations of the secondary waves at the shoreline evident in Figure 12 and also supported by the reduction of about $10 \%$ in the average swash period (not shown).

\section{Conclusions}

[29] Swash oscillations were observed to be strongly modulated by tide on an intermediate barred beach under mild wave conditions. The water depth over the offshore sandbar crest played a major role in controlling these modulations as it determined whether small waves broke over it or not according to the level of tide (i.e., water depth and therefore wave steepness over the crest). The concave profile may also have contributed to these tidal variations. These effects led to a tidal modulation in wave energy dissipation that ultimately controlled the energy driving the swash and hence its amplitude (even without significant changes in offshore wave conditions). The dissipation took essentially at incident frequencies and also resulted in the slope of the saturated region of the spectra becoming gentler.

[30] Swash hydrodynamics were found to be dominated by incident wave frequencies (consistent with the reflective slope) although this dominance became weaker during low tide as incident energy was increasingly dissipated by breaking over the bar. On the other hand, infragravity wave motions at the shoreline became more and more important as the tide decreased. We have provided evidence that secondary waves occur especially at low tide, and that the presence of these secondary waves might be related to an increase in the energy at infragravity frequencies through a mechanism of bore-bore capture.

[31] Significant runup height was found to increase by a factor of two at high tide compared to low tide, when most waves were breaking over the sandbar, and these changes were not observed to be modulated either by beach slope or by offshore wave conditions. This suggests that tidalinduced wave breaking dissipation might be a major process in controlling swash hydrodynamics on barred intermediate beaches under mild offshore wave conditions and can have significant implications for both parameterizations and modeling of runup oscillations on these systems.

[32] Acknowledgments. R.M.C.G. and G.C. were funded by the (New Zealand) Foundation for Research, Science and Technology. K.R.B. acknowledges the support of the Hanse Wissenschaftskolleg (Germany). Thanks to N. Plant for providing the code to estimate the water depth over the sandbar. Thanks also to G. Payne, J. Vangaalen, C. Hart, and R. Ovenden for help during the field experiment. This paper was greatly improved by comments and suggestions from the Associate Editor and two anonymous reviewers.

\section{References}

Aagaard, T., and J. Holm (1989), Digitization of wave run-up using video records, J. Coastal Res., 5(3), 547-551.

Aarninkhof, S. G. J., B. G. Ruessink, and J. A. Roelvink (2005), Nearshore subtidal bathymetry from time-exposure video images, J. Geophys. Res., 110, C06011, doi:10.1029/2004JC002791.

Baldock, T. E. (2006), Long wave generation by the shoaling and breaking of transient wave groups on a beach, Proc. R. Soc. A, 462, 1853-1876, doi:10.1098/rspa.2005.1642.

Baldock, T. E., and D. A. Huntley (2002), Long wave forcing by the breaking of random gravity waves on a beach, Proc. R. Soc. A, 458, 2177-2201, doi:10.1098/rspa.2002.0962.

Battjes, J. A., H. J. Bakkenes, T. T. Janssen, and A. R. van Dongeren (2004), Shoaling of subharmonic gravity waves, J. Geophys. Res., 109, C02009, doi:10.1029/2003JC001863.

Beji, S., and J. A. Battjes (1993), Experimental investigation of wave propagation over a bar, Coastal Eng., 19, 151-162, doi:10.1016/03783839(93)90022-Z.

Bogle, J. A., K. R. Bryan, K. P. Black, T. M. Hume, and T. R. Healy (2000), Video observations of rip formation and evolution, J. Coastal Res., 34, 117-127.

Bryan, K. R., and G. Coco (2010), Observations of nonlinear runup patterns on plane and rhythmic beach morphology, J. Geophys. Res., 115, C09017, doi:10.1029/2009JC005721. 
Butt, T., and P. Russell (2000), Hydrodynamics and cross-shore sediment transport in the swash-zone of natural beaches: A review, J. Coastal Res., 16(2), 255-268.

Ciriano, Y., G. Coco, K. R. Bryan, and S. Elgar (2005), Field observations of swash zone infragravity motions and beach cusp evolution, J. Geophys. Res., 110, C02018, doi:10.1029/2004JC002485.

Elfrink, B., and T. Baldock (2002), Hydrodynamics and sediment transport in the swash zone: A review and perspectives, Coastal Eng., 45, 149-167, doi:10.1016/S0378-3839(02)00032-7.

Elgar, S., and R. T. Guza (1985), Observations of bispectra of shoaling surface gravity waves, J. Fluid Mech., 161, 425-448, doi:10.1017/ S0022112085003007.

Elgar, S., R. T. Guza, B. Raubenheimer, T. H. C. Herbers, and E. L. Gallagher (1997), Spectral evolution of shoaling and breaking waves on a barred beach, J. Geophys. Res., 102(C7), 15,797-15,805, doi:10.1029/97JC01010.

Gorman, R., K. R. Bryan, and A. K. Laing (2003), Wave hindcast for the New Zealand region: Nearshore validation and coastal wave climate, N. Z. J. Mar. Freshwater Res., 37, 567-588, doi:10.1080/ 00288330.2003 .9517190

Guza, R. T., and E. B. Thornton (1982), Swash oscillations on a natural beach, J. Geophys. Res., 87(C1), 483-491, doi:10.1029/ JC087iC01p00483.

Haller, M. C., and P. A. Catalán (2009), Remote sensing of wave roller lengths in the laboratory, J. Geophys. Res., 114, C07022, doi:10.1029/ 2008JC005185.

Henderson, S. M., and A. J. Bowen (2002), Observations of surf beat forcing and dissipation, J. Geophys. Res., 107(C11), 3193 doi:10.1029/2000JC000498.

Holland, K. T., and R. A. Holman (1993), The statistical distribution of swash maxima on natural beaches, J. Geophys. Res., 98(C6), 10,271-10,278, doi:10.1029/93JC00035.

Holland, K. T., B. Raubenheimer, R. T. Guza, and R. A. Holman (1995), Runup kinematics on a natural beach, J. Geophys. Res., 100(C3), 4985-4993, doi: $10.1029 / 94 J C 02664$

Holland, K. T., R. A. Holman, T. C. Lippmann, J. Stanley, and N. Plant (1997), Practical use of video imagery in nearshore oceanographic field studies, IEEE J. Oceanic Eng., 22(1), 81-92, doi:10.1109/48.557542.

Holman, R. A. (1986), Extreme value statistics for wave run-up on a natural beach, Coastal Eng., 9, 527-544, doi:10.1016/0378-3839(86)90002-5.

Holman, R. A., and R. T. Guza (1984), Measuring run-up on a natura beach, Coastal Eng., 8, 129-140, doi:10.1016/0378-3839(84)90008-5.

Holman, R. A., and A. H. Sallenger (1985), Setup and swash on a natural beach, J. Geophys. Res., 90(C1), 945-953, doi:10.1029/JC090iC01p00945.

Howd, P. A., J. Oltman-Shay, and R. A. Holman (1991), Wave variance partitioning in the trough of a barred beach, J. Geophys. Res., 96(C7), 12,781-12,795, doi:10.1029/91JC00434

Huntley, D. A., R. T. Guza, and A. J. Bowen (1977), A universal form for shoreline run-up spectra?, J. Geophys. Res., 82(18), 2577-2581, doi:10.1029/JC082i018p02577.

Janssen, T. T., J. A. Battjes, and A. R. van Dongeren (2003), Long waves induced by short-wave groups over a sloping bottom, J. Geophys. Res., 108(C8), 3252, doi:10.1029/2002JC001515.

Lippmann, T. C., and R. A. Holman (1989), Quantification of sand bar morphology: A video technique based on wave dissipation, J. Geophys. Res., 94(C1), 995-1011, doi:10.1029/JC094iC01p00995.

Lippmann, T. C., R. A. Holman, and A. J. Bowen (1997), Generation of edge waves in shallow water, J. Geophys. Res., 102(C4), 8663-8679, doi:10.1029/96JC03722.

Longuet-Higgins, M. S., and R. W. Stewart (1964), Radiation stresses in water waves; a physical discussion, with applications, Deep Sea Res. $11,529-562$.

MacMahan, J. H., E. B. Thornton, and A. J. H. M. Reniers (2006), Rip current review, Coastal Eng., 53, 191-208, doi:10.1016/j.coastaleng.2005.10.009.

Mase, H. (1988), Spectral characteristics of random wave run-up, Coastal Eng., 12, 175-189, doi:10.1016/0378-3839(88)90004-X.

Masselink, G. (1995), Group bound long waves as a source of infragravity energy in the surf zone, Cont. Shelf Res., 15(13), 1525-1547, doi:10.1016/0278-4343(95)00037-2.
Masselink, G. (1998), Field investigation of wave propagation over a bar and the consequent generation of secondary waves, Coastal Eng., 33, 1-9, doi:10.1016/S0378-3839(97)00032-X

Miche, M. (1951), Le pouvoir réfléchissant des ouvrages maritimes exposés a l'action de la houle, Ann. Ponts Chaussees, 121, 285-319.

Okihiro, M., and R. T. Guza (1995), Infragravity energy modulation by tides, J. Geophys. Res., 100(C8), 16,143-16,148, doi:10.1029/ 95JC01545.

Peregrine, D. H. (1983), Breaking waves on beaches, Annu. Rev. Fluid Mech., 15, 149-178, doi:10.1146/annurev.fl.15.010183.001053.

Plant, N. G., K. T. Holland, and M. C. Haller (2008), Ocean wavenumber estimation from wave-resolving time series imagery, IEEE Trans. Geosci. Remote Sens., 46(9), 2644-2658, doi:10.1109/TGRS.2008.919821.

Raubenheimer, B., and R. T. Guza (1996), Observations and predictions of run-up, J. Geophys. Res., 101(C11), 25,575-25,587, doi:10.1029/ 96JC02432.

Ruessink, B. G. (1998a), Bound and free infragravity waves in the nearshore zone under breaking and nonbreaking conditions, J. Geophys. Res., 103(C6), 12,795-12,805, doi:10.1029/98JC00893.

Ruessink, B. G. (1998b), The temporal and spatial variability of infragravity energy in a barred nearshore zone, Cont. Shelf Res., 18, 585-605, doi:10.1016/S0278-4343(97)00055-1.

Ruessink, B. G., M. G. Kleinhans, and P. G. L. van den Beukel (1998), Observations of swash under highly dissipative conditions, J. Geophys. Res., 103(C2), 3111-3118, doi:10.1029/97JC02791.

Ruggiero, P., R. A. Holman, and R. A. Beach (2004), Wave run-up on a high-energy dissipative beach, J. Geophys. Res., 109, C06025, doi:10.1029/2003JC002160.

Sénéchal, N., P. Bonneton, and H. Dupuis (2002), Field experiment on secondary wave generation on a barred beach and the consequent evolution of energy dissipation on the beach face, Coastal Eng., 46, 233-247, doi:10.1016/S0378-3839(02)00095-9.

Sheremet, A., R. T. Guza, S. Elgar, and T. H. C. Herbers (2002), Observations of nearshore infragravity waves: Seaward and shoreward propagating components, J. Geophys. Res., 107(C8), 3095, doi:10.1029/ 2001JC000970.

Stockdon, H. F., R. A. Holman, P. A. Howd, and A. H. Sallenger (2006), Empirical parameterization of setup, swash, and runup, Coastal Eng., 53 573-588, doi:10.1016/j.coastaleng.2005.12.005.

Symonds, G., D. A. Huntley, and A. J. Bowen (1982), Two-dimensional surf beat: Long wave generation by a time-varying breakpoint, J. Geophys. Res., 87(C1), 492-498, doi:10.1029/JC087iC01p00492.

Thomson, J., S. Elgar, B. Raubenheimer, T. H. C. Herbers, and R. T. Guza (2006), Tidal modulation of infragravity waves via nonlinear energy losses in the surf zone, Geophys. Res. Lett., 33, L05601, doi:10.1029/ 2005GL025514.

Thornton, E. B., and C. S. Kim (1993), Longshore current and wave height modulation at tidal frequency inside the surf zone, J. Geophys. Res., 98(C9), 16,509-16,519, doi:10.1029/93JC01440.

van Dongeren, A., J. Battjes, T. Janssen, J. van Noorloos, K. Steenhauer, G. Steenbergen, and A. Reniers (2007), Shoaling and shoreline dissipation of low-frequency waves, J. Geophys. Res., 112, C02011, doi:10.1029/2006JC003701.

van Enckevort, I. M. J., and B. G. Ruessink (2001), Effect of hydrodynamics and bathymetry on video estimates of nearshore sandbar position, J. Geophys. Res., 106(C8), 16,969-16,979, doi:10.1029/1999JC000167.

K. R. Bryan and R. M. C. Guedes, Department of Earth and Ocean Sciences, University of Waikato, Private Bag 3105, Hamilton 3240, New Zealand. (kbryan@waikato.ac.nz; rmcg1@waikato.ac.nz)

G. Coco, National Institute of Water and Atmospheric Research, Gate 10 Silverdale Rd., PO Box 11-115, Hamilton, New Zealand. (g.coco@niwa. co.nz)

R. A. Holman, College of Oceanic and Atmospheric Sciences, Oregon State University, 104 Ocean Admin. Bldg., BURT 137, Corvallis, OR 97331, USA. (holman@coas.oregonstate.edu) 